\title{
Business Communication and COVID-19
}

\section{Geert Jacobs}

2020 President of the Association for Business Communication (ABC), Ghent University, Ghent, Belgium

It is of course too early to determine the impact of the global COVID-19 crisis on the discipline of business communication. Some might say that there will be no impact and that I am mistaken to raise the question at all. But let me reflect on it nevertheless. In doing so I will draw on, among other sources, a mini-corpus of earlier editorial articles in this journal in the hope that narrowing down our scope will prevent me from getting lost in the many possible details of this wide-ranging topic and create some focus and relevance in terms of the scholarly debate that Business Communication Research and Practice $(B C R P)$ is contributing to.

In a recent interview that was part of a video project on the past and present leaders of the Association for Business Communication (ABC), I was asked how business communication has changed since I started working in the field and what I thought was the most important contribution that the discipline has made to both scholarship and society. I answered that, from my perspective as a linguist, business communication has been fairly successful in infiltrating other disciplines, including linguistics. Business communication research and teaching has played a role in making business more central as a domain for scholarly inquiry in its own right.

I remember that when I wrote my $\mathrm{PhD}$ on press releases back in the 90s, other linguists looked at me and wondered if there was no other, more traditional set of data to work with. Two decades later, a significant number of linguists are engaging with business data and few receive questions about it. Some of the key principles of business communication seem to have moved center stage in society as a whole as well. Think of the way in which we value transparent, concise, and clear communication, not just in business, but also in our daily, personal interactions. Or think of crisis communication and the way in which some of its most popular do's and don'ts (like don't speculate or don't shift blame) have trickled down to the way in which we talk about our daily mishaps with colleagues, relatives, and friends.

This is how Marcel Robles opens her editorial to the first issue of the 2020 volume of BCRP: "Effective and efficient communication is of utmost importance for organizations to succeed" (Robles, 2020, p. 1). I believe this is a perfect illustration of the logic that seems to dominate much business communication, and it seems to be gaining traction elsewhere in society. Managers, Robles argues, should "practice better planning techniques to clarify and understand their ideas and company goals"; they should "know exactly how the task is to be completed, what resources are needed, sequence of activities, and timeline to completion." Alternatively, poor communication is characterized by "unclear instructions and responsibilities, meetings that serve no purpose" (p. 1). I would say a lot of this sentiment is now being extended to the ways in which we run our households, manage our interpersonal relationships, and even negotiate our individual identities.

But what does this mean in the current pandemic? I believe there may well be evidence to be found that, amidst the daily turmoil, we are insisting on clarity, planning, and effectiveness more than ever before. We expect it from our governments and employers alike. And in a way this is understandable: these are very uncertain times indeed, and we count on our elected officers and on our bosses to tell us exactly what should be done, to give us unambiguous guidelines that will help us navigate the storm. In other words, we hope for the kind of effective and efficient communication that Robles writes about in a business context, and it is not difficult to see why we are doing so.

At the same time, it may well be somewhat paradoxical, even unreasonable, to hope for certainty when, fundamentally, we know that nothing is certain and that today's guidelines are bound to be irrelevant tomorrow. It follows that the best our 
leaders can provide us with is an illusion of certainty and that there is a distinct danger that we will end up frustrated with inevitably ever-changing and less than fully effective or efficient rules and regulations. So my point is that it may well be worth questioning this dominant logic and exploring how our communication efforts can help people (citizens, employees, customers, shareholders) embrace uncertainty and how nuance, critique and narrative may be just as powerful as (and now perhaps even more powerful than) clarity, completeness, and accuracy.

In a way, this is nothing new. Nuance, critique, and narrative have always been strong features of the discipline of business communication. Jim Dubinsky draws our attention to these themes in his 2019 editorial in this journal. Describing the first ABC Europe conference in Helsinki, Finland, in 1999 as one of what he calls three "historical moments that capture critical inquiry" (Dubinsky, 2019, p. 1), Dubinsky writes that the conference was instrumental in pointing to "the baseline need to study communication in situ, to understand what businesses are doing, the kinds of genres they are using or adapting, and how technologies and new media are impacting their practice" (p. 3). Dubinsky's words echo Richard Rumelt's (2011) observation in Good Strategy/Bad Strategy that, in the end, all of his case-based MBA classes are about a single question: "What's going on here?"; they are not about "deciding what to do, but [about] the more fundamental problem of comprehending the situation" (Rumelt, 2011, p. 79).

I came across the Rumelt quote in Radical Uncertainty, in which Kay and King (2020) argue that, in assessing management problems, too many people "get immersed in technicalities, engaged in day-to-day preoccupations" and fail to stand back and ask, "What is going on here?" (p. 10). Their main thesis is that we need to kick our addiction to thinking in terms of mathematical probabilities in situations where they make no sense and acknowledge that policy makers, businesses, and households are not always about optimizing processes (in other words, efficiency and effectiveness) but rather about coping (getting along on a day to day basis). Radical Uncertainty was published (just) before the outbreak of the global COVID-19 pandemic, but it is not difficult to see how Kay and King's argument can be applied to what we are currently going through. In fact, at one point they offer a clue themselves when they suggest that " $[\mathrm{t}] \mathrm{o}$ describe catastrophic pandemics, or environmental disasters, or nuclear annihilation, or our subjection to robots, in terms of probabilities is to mislead ourselves and others. We can talk only in terms of stories" (p. 40).

Returning to Dubinsky's editorial, another of his three "historical moments that capture critical inquiry" is the panel on
"Business Communication Research: Past, Present and Future," which was convened by Jim Suchan and Mirjaliisa Charles at the 2006 ABC Annual Conference. The panel and the ensuing series of short articles published in Business Communication Quarterly, Dubinsky argues, "described the importance of research methods such as ethnography, case analysis, and genre studies" and called for interdisciplinary and multicultural exploration. I'd like to briefly go into this observation in order to make two final points, one on methodology in business communication research, the other on internationalization.

First, it should be clear that the methods identified here align with Kay and King's emphasis on finding out what is going on, making sense of what's happening rather than quantifying or forecasting (Kay \& King, 2020). One of their key features-ethnography, in particular-is reflexivity, i.e., reflection on our own beliefs and actions and on how they essentially impact on what is going on. It is important to note here that reflexivity is not just a defining trait of much qualitative inquiry; it is what characterizes most, if not all, communication, in business settings and elsewhere. To give just one (business) example: whatever a chairman or chairwoman writes in his or her opening to a corporation's annual financial report is not just a reflection of the organization's current state; it is equally a force that will impact it. As a linguist, I would say that there is a certain performativity involved. Amid this pandemic, it is more crucial than ever to be aware of the essential reflexiveness (or performativity) of all (business) communication-and of their implications for research methodology. Speaking or writing (or tweeting, for that matter) is not just describing a state of affair; it means acting on it, it is crucial to take this into account as we select the appropriate tools from our methodological toolbox.

Second, as for internationalization, it needs to be added that Dubinsky primarily turns to the panel and to the ABC Europe conference in Helsinki as milestones in the internationalization of the discipline. The publication of the first issue of $B C R P$ was another milestone marking another step in the global development of business communication. Towards the end of the editorial, Dubinsky argues that as national borders continue to disappear, all crises are global and that they lead to more internationalization (cf. also Pinsdorf, 2004). I must say that I am not sure this is always the case. Again, it's too early to tell but when-at some point in the future-we have the benefit of distance, we may well conclude that the global pandemic has led us to fall back on ourselves, with national governments obsessing with their own statistics and their own policies. Paradoxically, however, it could be argued that this return to fragmentation and diversity may make cross-country scholarly analysis even more relevant and necessary and thus provide another boost to 
the internationalization of the discipline.

All of the above seems to tie in with Yung Ho Suh's call in one of the journal's 2018 editorials for "more discussion on social responsibility and ethical issues in business," for business communication "to more effectively connect to larger issues [...] and to adapt to increasingly international issues" (Suh, 2018, p. 51). Engaging with the radical uncertainty that COVID-19 is pressing on us can be seen as an act of (C)SR, for researchers and teachers as well as for practitioners. So let's start thinking about the world and scholarship that lie ahead of us. In doing so, it would be wise to engage in reflexiveness and take on the kind of international perspective that has characterized some of the earlier editorials of this journal.

\section{References}

Dubinsky, J. (2019). Internationalizing the Association for Business Communication: A long journey, one step at a time. Business Communication Research and Practice, 2(1), 1-4.
Kay, J., \& King, M. (2020). Radical uncertainty: Decision-making for an unknowable future. London, UK: The Bridge Street Press.

Pinsdorf, M. K. (2004). All crises are global: Managing the escape chaos. New York, NY: Ford University Press.

Robles, M. M. (2020). "Ups and downs" and "Ins and outs" of organizational communication. Business Communication Research and Practice, 3(1), 1-3.

Rumelt, R. (2011). Good strategy/bad strategy: The difference and why it matters. New York, NY: Crown Business.

Suh, Y. H. (2018). Business communication with corporate social responsibility. Business Communication Research and Practice, 1(2), 51-53.

Geert Jacobs

Department of Linguistics, Ghent University, Campus Ufo, Rectorate, Sint-Pietersnieuwstraat 25, B-9000 Ghent, Belgium Tel: +32-9-264-35-29, E-mail: geert.jacobs@ugent.be 